\title{
A LEPRA NO CEARÁ E NO ESPÍRITO SANTO (1920-1940): OLHARES E REFLEXÕES
}

SEBASTIÃO PIMENTEL FRANCO* UNIVERSIDADE FEDERAL DO ESPÍRITO SANTO VITÓRIA - ESPÍRITO SANTO - BRASIL

ZILDA MARIA MENEZES LIMA** UNIVERSIDADE ESTADUAL DO CEARÁ FORTALEZA - CEARÁ - BRASIL
RESUMO

ABSTRACT

Este ensaio pretende estabelecer alguns níveis de compreensão acerca do combate à lepra nos estados do Ceará e do Espírito Santo, a partir das ações impetradas por grupos filantrópicos bem como por poderes e saberes nacionais e locais. Nosso objetivo é propor uma reflexão que possibilite algum entendimento nos modos como os dois estados em tela, assimilaram e puseram em prática tais ações, principalmente, no período situado entre as décadas de 1920 e 1940. Afirmarmos que as ações caritativas da sociedade cearense foram muito importantes na implementação do isolamento compulsório com pouca intervenção estatal; já no Espírito Santo foi fundamental a ação dos poderes instituídos na implementação de políticas públicas no combate à doença, embora registremos a também importância da sociedade por meio das camadas mais endinheiradas, que atuando em conjunto com o Estado, buscaram alternativas para apoiar muitas vezes financeiramente o projeto de saneamento da lepra. Embora a política pública de Estado em relação a lepra chegasse aos estados da Federação de forma uniforme, detectamos similitudes, mas também diferenças em como se deu a criação dos leprosários e de como esses funcionaram no Ceará e no Espírito Santo. Utilizamos como fontes, periódicos do Ceará e do Espírito Santo, Relatórios administrativos da direção dos leprosários, Relatório de Presidentes de Província, Correspondências recebidas pela administração dos leprosários, relatório de atividades do Serviço de Lepra.

Palavras-chave: Leprosário de Canafístula; Leprosário de Itanhenga; Lepra; Ceará; Espírito Santo.

The present text aims at establishing certain levels of understanding about the fight against leprosy in two states of the Brazilian Federation: Ceará and Espírito Santo, between the $1920 \mathrm{~s}$ and $1940 \mathrm{~s}$. We indicate that the creation of leprosariums in Ceará (Canafístula) in 1928 and in Espírito Santo (Itanhenga) in 1937 enabled effective actions to combat this disease which was reckoned at the time as hideous. We assert that the charitable actions of the society in Ceará were very important in the implementation of compulsory isolation with little state intervention; as of Espírito Santo, the action of the instituted powers in the implementation of public policies in the fight against the disease was fundamental. We also notice there, however, the importance of society through the more affluent strata, who working together with the State, sought alternatives to support the leprosy sanitation project financially. Although the public policy of the State regarding leprosy reached the states of the Federation in a uniform manner, we detect similarities but also differences in how leprosariums were created and how they worked in Ceará and Espírito Santo. We used, as sources, periodicals from Ceará and Espírito Santo, administrative reports from the management of the leprosariums, reports by Presidents of Provinces, mail received by the management of the leprosariums, Leprosy Service activity report.

Keywords: Canafistula leprosarium; Itanhenga leprosarium; Leprosy; Ceará; Espírito Santo.

\footnotetext{
* Doutor em História (USP) e Professor do Programa de Pós-Graduação em História da Universidade Federal do Espírito Santo (UFES). Email: sp.franco61@gmail.com

** Doutora em História (UFRJ) e Professora Associada da Universidade Estadual do Ceará (UECE). E-mail:zilda.lima@uece.br
} 


\section{INTRODUCÃO'}

Ações efetivas de combate à lepra² ${ }^{2}$ somente foram observadas no Ceará e no Espírito Santo a partir da construção/funcionamento dos leprosários nos dois estados. Na década de 1920 foi erguido o primeiro leprosário cearense (1928) e sua edificação representou a prática mais corriqueira de uma suposta atenção aos leprosos no Ceará. No Espírito Santo, embora os dados apontados pela Estatística de Leprosos do Brasil realizada em 1877 indiquem um total de 28 casos, somente a partir de 1930, com a inauguração de seu Leprosário Modelo $(1937),{ }^{3}$ foram observados esforços no sentido tentar conter o avanço da doença.

As primeiras ações de enfrentamento à enfermidade nos dois estados se dão, portanto, a partir da edificação dos dois leprosários: o da Canafistula (CE) e o de Itanhenga (ES). No caso do Ceará, fica claro que campanhas realizadas pela igreja católica e ações pontuais da sociedade em geral foram fundamentais para a construção do primeiro leprosário. Já no Espírito Santo, o Leprosário de Itanhenga foi fruto dos avanços do interesse "oficial" pela enfermidade, marcado por práticas conjuntas do Governo Federal e Estadual bem como do esforço pessoal do Dr. Pedro Fontes ${ }^{4}$.

\section{A LEPRA E O GOVERNO FEDERAL: CAMINHOS TORTUOSOS...}

Em 1916, o médico Miguel Pereira, sanitarista, teria dito que o Brasil era um imenso hospital, sobretudo a população que vivia nos sertões, o que resultaria numa população doente,

\footnotetext{
${ }^{1}$ Este texto é resultado do projeto de pesquisa “As múltiplas vivências do isolamento compulsório no leprosário de Itanhenga, Espírito Santo: história e interpretações" financiado pela FAPES.

${ }^{2}$ Utilizamos aqui o termo "lepra" para não incorrer em anacronismo, posto que o uso do termo "hanseníase" ainda não era usual, bem como usamos a palavra "leproso" pela mesma razão.

${ }^{3}$ Principalmente, após o Estado Novo, a ampliação dos recursos financeiros para o setor da saúde e, mormente, para o combate à lepra foram ampliados. No citado período são ampliados o Dispensário Oswaldo Cruz no Ceará e vários Dispensários no Espírito Santo, bem como posteriormente, a construção dos Preventório Eunice Weaver e Alzira Blay, instituições modelares para isolamento em terras alencarinas e capixabas, dos filhos indenes de leprosos. Sobre esse assunto indicamos a leitura de:

${ }_{4}^{4}$ Pedro Fontes diplomou-se pela Faculdade de Medicina da Bahia no ano de 1903. Apresentou como tese de final do curso "estudo sucinto de uma das modalidades da demência precoce; a variedade paranoide". Chegou ao Espírito Santo em 1917, quando havia sido transferido do Serviço de Saneamento Rural do Distrito Federal onde trabalhava, para assumir a chefia da Inspetoria de Profilaxia da Lepra e Doenças Venéreas. Tão logo assumiu esta Inspetoria, iniciou o trabalho de recenseamento dos leprosos existentes no Espírito Santo, o que possibilitou conhecer-se que o número de leprosos era muito superior ao que se pensava anteriormente. Já em 1931 se sabia por este recenseamento que o número de leprosos era de pelo menos de 370 doentes, bem maior que os 22 casos notificados em 1927. Sobre esta questão ler: FRANCO, Sebastião Pimentel; SILVA, Simone Santos de Almeida. Os depoimentos e o cotidiano da Colônia de Itanhenga no Espírito Santo: apontamentos iniciais. In: MAGALHÃES, Sonia Maria de; SILVA, Leicy Francisca da; MACIEL, Roseli Martins Tristão. História de doenças; percepções, conhecimentos e práticas. São Paulo: Alameda, 2017. p. 313-338.
} 
improdutiva, com falta de iniciativa. ${ }^{5}$ Nessa época, o alvo da atenção governamental eram doenças como a ancilostomíase, malária, febre amarela, tuberculose e, somente nos anos seguintes, com o avanço dos casos de lepra, as ações de combate à esta enfermidade, exigiram intervenção do Estado, que passou a considerá-la endêmica nacionalmente. Uma das ações para buscar resolver o problema dessa grave doença foi a criação da Inspetoria de Profilaxia da Lepra e Doenças Venéreas em 1922.

Para tanto, diversos estados da Federação e a União fizeram parcerias, sendo estabelecidos nas unidades federativas os Serviços de Profilaxia da Lepra e Doenças Venéreas. A parceria realizada para esse serviço acabou não prosperando e, em 1926, esse serviço foi desativado por ser considerado ineficiente. Entretanto, o serviço de Profilaxia da Lepra continuou existindo, ligado à Diretoria de Higiene em alguns estados, como foram os casos do Ceará e do Espírito Santo.

É sabido que no Brasil, as medidas adotadas no sentido de compor, inicialmente, uma agenda para a saúde pública e, posteriormente, ações mais coordenadas visando o bem-estar geral da população partiram de iniciativas governamentais que envolveram, grosso modo, o governo central e os governos estaduais de acordo com os interesses políticos em voga, capacidade administrativa e poder econômico de cada estado ${ }^{6}$. Desse modo, a luta contra lepra acompanhou também a dinâmica de cada estado, embora os leprosários, asilos e afins, na sua grande maioria sem nenhuma estrutura física ou de assistência médica, tenham sido a tônica geral para isolar os leprosos.

\section{AS ACÕES SANITÁRIAS NO CEARÁ E O LEPROSÁRIO ANTÔNIO DIOGO}

A instauração dos primeiros aparatos em saúde pública no Ceará foi lenta devido a uma série de questões. Do ponto de vista econômico, somente a partir do século XIX, o Ceará foi inserido na lógica do mercado internacional, em grande monta, em virtude da produção algodoeira. Com o crescimento desta, marcado pela procura do produto no mercado

\footnotetext{
${ }^{5}$ LIMA, Nísia Trindade; HOCHMAN, Gilberto. Condenado pela raça, absolvido pela medicina: o Brasil descoberto pelo movimento san itarista da Primeira República. In: MAIO, Marcos Chor, SANTOS, Ricardo Ventura (Org.). Raça, ciência e sociedade. Rio de Janeiro: Fiocruz, Centro Cultural Banco do Brasil, 1996, p. 23-49.

${ }^{6}$ LIMA, Z. M. M. Uma Enfermidade à flor da Pele: A Lepra Em Fortaleza (1920-1937). Coleção Outras Histórias - 59. Secretaria de Cultura do Ceará/Museu do Ceará, Fortaleza, 2009. p 43.
} 
internacional, foi observado um sensível crescimento da capital da Província, que vai experimentar um relativo desenvolvimento urbano. No entanto, as questões referentes à saúde da população encontravam-se inseridas no âmbito da filantropia e/ou nos auxílios emergenciais do governo federal em momentos de calamidade. Do ponto de vista político, as oligarquias encasteladas nos cargos de mando no Estado, não priorizavam ações de higiene ou estabeleceram de modo pontual uma agenda de saúde pública em período anterior à década de 1920.

No que tange aos consórcios com o Governo Federal, em agosto de 1921 foi inaugurado o Serviço de Profilaxia da Lepra e Doenças Venéreas no Ceará. Tal serviço era da alçada da Inspetoria da Lepra e Doenças Venéreas (ILDV) diretamente subordinada à diretoria do Departamento Nacional de Saúde Pública (DNSP). Em Fortaleza, a ILDV priorizava as chamadas "doenças venéreas" em virtude dos casos de sífilis na capital, serem considerados alarmante. Assim, o Dispensário Oswaldo Cruz, inaugurado em 1922, passou a abrigar a ILDV, realizando os serviços referentes ao tratamento das "enfermidades venéreas" bem como da lepra.

A partir de 1920, informações acerca da presença de leprosos nos principais logradouros da capital tomam as páginas dos principais jornais:

Porque, na verdade, a morphéa vai tomando vulto em Fortaleza, sem que se tome, qualquer iniciativa para evitar-lhe o desenvolvimento constante pelos descuidos das autoridades sanitárias. Não é admissível que Fortaleza continue a ser diariamente perlustrada por leprosos que andam por toda parte, pelas ruas, mercados, cafés, avenidas, pelos pontos mais centrais, enfim, propagando o gérmen de seu terrível mal ${ }^{7}$.

Tanto quanto as moléstias venéreas e as endemias rurais, que a comissão sanitária está combatendo nos postos de profilaxia do interior, a morphéa lhe deveria merecer os mais sérios cuidados. As autoridades sanitárias precisam urgentemente, enfrentar o problema do alastramento da morphéa e resolvê-lo com vontade. A população de Fortaleza, assim como a de todo o estado, espera animosamente, as suas providências ${ }^{8}$.

\footnotetext{
${ }^{7}$ O Nordeste, $1921, \mathrm{p} 02$

${ }^{8}$ O Nordeste, 1922, p 02.
} 
Foi indubitavelmente a imprensa, e principalmente o jornal $O$ Nordeste, que trouxe à tona “o problema” e mais se pronunciou a respeito da expansão da lepra no Ceará. A expressão "mal de Lázaro" passou a pontuar as manchetes deste periódico e seria na capital, Fortaleza, que grande número de leprosos vivia sem nenhuma vigilância, desenvolvendo todo tipo de atividades:

\begin{abstract}
O mal de Lázaro cada dia se alastra mais. Nesta capital, percorrendo os pontos centrais, residindo nas ruas mais habitadas, vendendo frutas, legumes e tabuleiros, penetrando nas moradias particulares e nas repartições públicas, nos restaurantes e nos cafés, pedindo esmola, exercendo, enfim toda sorte de atividades, nós vemos todos os dias, morféticos em estado grave, que se põem em contacto perigoso com a população sã .
\end{abstract}

As notícias destacavam sempre o "perigo" que representava para a população sã a convivência com os "lázaros", pela possibilidade da transmissibilidade. Encarados com benevolência ou rejeitados só era facultado aos leprosos um destino comum: viverem afastados do convívio com as pessoas sãs. Como se pode observar, uma das maiores preocupações aventadas pela imprensa era o fato de muitos "lázaros" não só compartilharem do cotidiano da cidade, mendigando, mas também porque continuaram a desenvolver suas atividades profissionais sem que as autoridades sanitárias tomassem qualquer providência.

No Ceará, os primeiros espaços de segregação destinados aos leprosos não chegaram a se constituir em asilos. Por volta de 1923 é que começaram a ser tomadas as primeiras medidas efetivas para a retirada dos leprosos das ruas, com a construção de palhoças no Arraial Moura Brasil $^{10}$, iniciativa tomada pela Liga das Senhoras Católicas (LSC) e que redundou em retumbante fracasso.

Uma segunda tentativa foi encetada por volta de 1925, quando os enfermos, que perambulavam pela cidade, foram recolhidos ao Morro do Croatá ${ }^{11}$, onde foram construídas novas palhoças, afastadas das áreas mais habitadas e do convívio com as pessoas saudáveis.

\footnotetext{
${ }^{9}$ O Nordeste, 1923, p 02.

${ }^{10}$ O Arraial Moura Brasil é hoje um pequeno bairro de Fortaleza. LEITE FILHO, R. A História de Fortaleza passa por esta rua.. Fortaleza: Edições Demócrito Rocha, 2007, p. 23.

${ }^{11} \mathrm{O}$ Morro do Croatá localizava-se próximo à estação ferroviária João Felipe, hoje região central da cidade é uma das estações do metrô de Fortaleza. LEITE FILHO, 2007, p. 23.
} 
Em nota oficial ao Diário do Ceará a secretaria do governo do Estado informou naquela ocasião:

Muito antes de se cogitar da construção em Canafístula, do leprosário, o Governo, de acordo com o Diretor de Saneamento Rural e no intuito de retirar para um local isolado os leprosos que perambulavam pelas ruas de Fortaleza, resolveu mandar edificar, na praia do Pirambú um abrigo para os infelizes acometidos do terrível mórbus. Não dispondo de fundos para tal serviço, dirigiu o governo, por intermédio do Secretário da Presidência, um apelo aos prefeitos municipais que contribuíram de acordo com suas possibilidades, sendo toda a quantia aplicada na construção daquele abrigo ${ }^{12}$.

O abrigo citado nunca foi realmente ocupado pelos doentes, os quais por lá apareciam esporadicamente e não cumpriam as determinações de se manterem isolados, apesar de uma comissão, da qual fazia parte Monsenhor Tabosa, Dr. Amaral Machado, Dr. Luís Moraes Correia e o Cel. Antônio Diogo - insuspeitos cidadãos fortalezenses reconhecidamente envolvidos nas campanhas pela edificação do leprosário - tenham declarado assistir aos leprosos de Fortaleza, abrigados naquele asilo improvisado ${ }^{13}$.

A imprensa cearense acompanhou de perto o debate para a edificação do primeiro leprosário cearense. Um leprosário nos anos de 1920, neste estado, seria em primeira instância um abrigo para isolar os doentes do contato com as pessoas saudáveis. Se a questão principal consistia em afastá-los, então o local de isolamento deveria situar-se distante dos núcleos com maior densidade populacional. Nesse sentido, a definição do local para a construção de um leprosário era sempre polêmica e envolvia uma série de interesses. Em virtude do estigma em torno da doença, ninguém desejava o leprosário nas suas cercanias.

Segundo o Boletim Comemorativo das Bodas de Prata da Colônia da Canafístula ${ }^{14}$, depois Colônia Antônio Diogo, o benemérito que lhe deu o nome foi quem saiu do discurso para a ação no sentido mais literal do termo, quando da edificação da referida instituição. Assim,

\footnotetext{
${ }^{12}$ Diário do Ceará, 1925, p 03.

${ }^{13}$ Após três anos de pressão da imprensa, principalmente do jornal $O$ Nordeste $e$ da classe médica, é que foi iniciado o debate acerca do local em que deveria ser edificado o primeiro leprosário cearense. LIMA, Z.M.M. O Grande Polvo de Mil Tentáculos: a lepra em Fortaleza (19201945). 292 f. TESE (Doutorado em História Social) - Universidade Federal do Rio de Janeiro, Rio de Janeiro, 2007. p 78.

${ }^{14}$ Canafístula era o nome do Distrito em que foi erguido o Leprosário. Posteriormente, o leprosário recebeu o nome de Antônio Diogo, em homenagem ao seu principal benemérito. Hoje, o citado distrito também se chama Antônio Diogo.Boletim Comemorativo das Bodas de Prata da Colônia da Canafístula, agosto, 1953, p.27.
} 
também segundo a imprensa da época, teria o Coronel Antônio Diogo, um rico comerciante cearense, empregado uma alta quantia na construção da leprosaria e ainda, teria acompanhado diariamente, os passos da sua edificação. Nos últimos dias do ano de 1926, publicou o jornal Correio do Ceará:

A planta da Colônia dos Leprosos já está devidamente preparada. È um conjunto de casas, em grupo que forma uma espécie de cruzeiro. A haste principal da cruz será ocupada no seu pé, próxima à povoação, pelas seguintes habitações: seis casas para os empregados, uma para o porteiro, outra para o diretor, outra para um instituto de terapêutica, outra para uma creche e alojamento de crianças, outras ainda para administração, farmácias e laboratórios, dispensa, escola, armazém, rouparia e pavilhão de observação. No centro da haste, no terreno propriamente da colônia, ficará em quadro, um grupo de 32 casas, oito em cada face, destinada aos casados que ali se asilarem. Dentro do quadro serão situadas a capela e a lavanderia. $\mathrm{Na}$ extremidade dessa haste estão 14 casas para os contribuintes. Os braços da cruz serão representados de um lado e de outro por dois grupos de 16 casas, em quadro, sendo quatro em cada face. Num dos lados serão alojados os homens solteiros, do outro, as moças. Há também os terrenos destinados ao cemitério e necrotério e aos estábulos ${ }^{15}$.

Desse modo, o primeiro Leprosário cearense foi edificado no Distrito da Canafístula, sem observância à planta original amplamente apresentada à imprensa em razão da ausência dos recursos financeiros necessários. Segundo o Boletim já citado, a instituição iniciou seu funcionamento sem obedecer aos requisitos formalmente exigidos a um estabelecimento da sua natureza. O Regimento do DNSP de 1923, referente à Profilaxia Especial da Lepra no artigo 141 informava:

A instalação de estabelecimentos destinados a leprosos obedecerá a condições de conforto e aprazibilidade para os doentes e de proteção para as populações vizinhas, ficando subordinado o funcionamento deles a instrução expedida pelo Distrito Federal depois de aprovada pelo Ministério da Justiça e Negócios Interiores. $^{16}$

\footnotetext{
${ }^{15}$ Correio do Ceará, 1926, p 02.

${ }^{16}$ Regimento do Departamento Nacional de Saúde Pública, 1923, p 179.
} 
O artigo 139, esclarecia que as áreas destinadas aos leprosários deveriam ter amplitude para nelas serem estabelecidas "verdadeiras Villas de Leprosos" com capacidade para posterior ampliação. Daí a necessidade de serem erguidas “em lugares onde a par das melhores condições higiênicas existam amplos logradouros numa extensão nunca inferior a 500 metros quadrados". Rezava o mesmo artigo que a instituição deveria comportar um hospital e uma creche e que eram absolutamente necessárias áreas para culturas agrícolas, por isso era muito importante a necessidade da observância do solo e espaço para a criação de animais.

[...]será permitida a fundação e manutenção de estabelecimentos nosocomiais para leprosos por pessoas ou associações privadas (...) que só podem funcionar mediante licença da Inspetoria da Profilaxia da Lepra, sujeitas à sua vigilância e obrigados a executar as medidas sanitárias necessárias ${ }^{17}$.

O excerto acima do mesmo artigo 139, esclarecia ainda que as instituições nosocomiais para leprosos deveriam observar os três modelos sugeridos: Colônias Agrícolas, Sanatórios ou Hospitais e Asilos. As colônias agrícolas, sempre preferíveis, deveriam ter bastante amplitude para que pudessem ser estabelecidos hospitais para os que necessitassem de cura de doenças e afecções intercorrentes, creche, orfanato e asilo para os incapazes. Os sanatórios, hospitais e asilos só seriam admitidos quando o reduzido número de doentes dispensasse o estabelecimento de uma colônia ${ }^{18}$.

Em $1^{\circ}$ de agosto de 1928, foi solenemente inaugurado o Asilo da Canafístula, na presença das mais representativas autoridades do Estado. Bastante reduzido em relação ao seu projeto original, o primeiro leprosário cearense foi assim definido pelo periódico O Nordeste: “A colônia de leprosos sita em Canafístula, é composta de uma vila com 64 casinhas isoladas com cômodos para 180 enfermos. Há também a casa da cura d'almas e da administração ainda em construção e mais nada" 19 .

\footnotetext{
${ }^{17}$ Regimento do Departamento Nacional de Saúde Pública, 1923, p 176.

${ }^{18}$ O Leprosário da Canafístula não se enquadrava em nenhuma das classificações estabelecidas pelo Regimento. Não se constituía em Colônia porque não possuía as instalações necessárias sugeridas; não era hospital porque não possuía o aparelhamento médico-ambulatorial minimamente aconselhável e não podia, em tese, ser asilo porque o Ceará possuía um número de leprosos suficiente para justificar uma colônia agrícola. No entanto, pelas suas características e modo de funcionamento, o primeiro leprosário cearense se configurou, efetivamente, num grande Asilo para os acometidos da lepra.

${ }^{19}$ O Nordeste, 1928, p.1.
} 
O primeiro leprosário cearense portava instalações físicas extremamente precárias, sem luz e sem um sistema de água adequado. Eram mínimas as possibilidades de prestar atendimento médico especializado visto que o médico que visitava o leprosário, o fazia duas vezes por semana e a medicação estava sempre em falta. Concluímos então que a construção do leprosário cearense objetivou atender a duas necessidades urgentes: evitar o "espetáculo" dos leprosos perambulando pelas ruas da capital e tranquilizar a população apavorada, diante da ameaça do contágio, na medida em que o perigo era afastado para longe do maior centro urbano do Estado $^{20}$.

Enfatizava o periódico que agora mais do que nunca, estaria a instituição necessitada do auxílio dos poderes públicos e do povo em geral, pois além da simplicidade das suas instalações, havia ainda a responsabilidade de alimentar aquelas pessoas e, principalmente, garantir algum tratamento para sua moléstia. De qualquer modo, ressaltava que se o leprosário não oferecia conforto, pelo menos havia retirados os leprosos de Fortaleza das ruas, pois até então, "viviam em grande promiscuidade".

Em 09 de agosto de 1928, foi transportada a primeira turma de enfermos para o leprosário, em um vagão isolado num trem da Rede de Viação Cearense (RVC). Saíram de Fortaleza em número de 35 doentes e mais sete foram recolhidos em outras estações, totalizando um número de 42, os primeiros enfermos a serem isolados na Canafístula. A composição do trem estava assim disposta: um carro aberto para o transporte de bagagem dos doentes, uma prancha que faria o transporte dos doentes da Estação da Canafístula até o Leprosário, um carro de passageiros exclusivamente para os leprosos e um carro especial para o médico e o sacerdote ${ }^{21}$

Em muitos leprosários foi observada a separação de doentes com base na posição social e econômica. Assim, a separação clássica era aquela havida entre os enfermos contribuintes e os indigentes. No Organização de Leprosários, Dr. Lincoln Continentino, Chefe do Serviço de

\footnotetext{
20 Tais constatações não minimizam o trabalho hercúleo que foi necessário para a construção e posterior funcionamento da Colônia da Canafístula. Nesse sentido, observou-se um consórcio entre vários grupos interessados na sua edificação e, consequentemente, no isolamento dos "lázaros": médicos, particulares, os poderes municipal e estadual, embora os esforços dispensados em maior escala e de modo muito pontual, tenham sido os da igreja católica, através das ordens religiosas e das várias associações e grupos que coordenava. Embora toda a campanha para a edificação do Asilo tenha se dado sob a gestão do Presidente do Estado José Moreira da Rocha (1924-1928), a inauguração oficial ocorreu já sob os auspícios do Presidente José Carlos de Matos Peixoto (1928-1930). Nesse momento, a presidência do Serviço de Saneamento Rural no Ceará estava sob a incumbência do Dr. Francisco do Amaral Peixoto.

${ }^{21}$ Ficou a cargo do Dr. Antônio Justa a direção clínica do abrigo da Canafístula. A administração geral foi entregue a três freiras da Ordem Franciscana. A manutenção do estabelecimento ficou sob responsabilidade de uma comissão criada para este fim, presidida por Monsenhor Tabosa e auxiliada por Antônio Diogo e Antonio Justa. Não é demais lembrar que a Direção Geral de um Leprosário era entregue a um médico diretor que geralmente, realizava todas as tarefas clínicas sozinho, exceto quando podia contar com a colaboração de médicos auxiliares, o que era raro.
} 
Engenharia Sanitária do Estado de Minas Gerais, aconselhava, além da divisão já citada baseada na hierarquia social, a separação entre os leprosos educados e analfabetos; entre crianças e adultos; loucos e criminosos e de um modo geral que "fosse respeitada a hierarquia peculiar a todas as sociedades humanas.

$\mathrm{Na}$ Leprosaria da Canafístula, havia rigorosa separação sexual entre os doentes solteiros no âmbito das habitações, embora, durante a produção de algum trabalho, jogos e estudos, pudessem ficar reunidos sem distinção de sexo. $\mathrm{O}$ casamento entre os enfermos era permitido desde que fossem comprovadamente solteiros ou viúvos, porém, a critério da autoridade sanitária e subordinada ao estágio e forma clínica da moléstia. Sabe-se também que a intervalos regulares, era eleito entre os doentes um prefeito - espécie de autoridade que atuava como intermediário entre os isolados e as autoridades sanitárias - para receber as reclamações dos seus pares e supostamente, defender perante a administração, os interesses dos doentes ${ }^{22}$.

Difícil e penoso era o trabalho dos médicos que prestavam serviços aos internos. Como a instituição era filantrópica, não havia salário. As dificuldades para clinicar no Abrigo da Canafístula começavam pelo deslocamento. Dr. Walter Porto, que em alguns momentos acompanhou o Dr. Antônio Justa ${ }^{23}$ nas visitas médicas à leprosaria, narrou no artigo abaixo um pouco do cotidiano médico na instituição:

[...] quer pela Estrada de Ferro, quer de automóvel, as viagens eram desconfortáveis, mormente, para quem as empreendia sem obrigação funcional e já em idade avançada. Comumente partíamos de madrugada (4 horas) e estávamos de volta em Fortaleza às 20 horas quando o trem não atrasava, o que era frequente. A maioria das vezes chegávamos depois da meia-noite, devido aos empecilhos comumente verificados nas viagens ferroviárias. Quando chegávamos à Estação da Canafístula, cobríamos a pé, os três quilômetros que distam do Prédio da Administração.

Após ligeiro repouso de alguns minutos, entrávamos na zona destinada aos doentes onde começávamos nossa via-crucis. Nos primeiros contatos a impressão era aterradora diante do número de mutilados e prostrados, bem como diante do quadro sanitário da colônia.

\footnotetext{
${ }^{22}$ Boletim Comemorativo das Bodas de Prata da Colônia da Canafístula, 1953b, p.12.

${ }^{23}$ Dr. Antônio Justa foi batizado pela imprensa como "o Pai dos Lázaros Cearenses" pela sua dedicação no acompanhamento aos leprosos isolados na Canafístula.
} 
A princípio duas vezes por semana, depois semanalmente, passávamos 5 horas em convívio com os doentes, auscultando e receitando seus males físicos e ouvindo suas queixas e lamúrias.

As dificuldades eram enormes. Tínhamos de vasculhar o pequeno depósito da farmácia da Colônia, à procura do medicamento receitado ou de algum sucedâneo o que infelizmente quase sempre não conseguíamos ${ }^{24}$.

No já citado artigo, Dr. Walter Porto não deixou também de enfatizar o estado clínico e psíquico dos pacientes, além de denunciar as condições sanitárias do leprocômio:

[...] as intercorrências mórbidas múltiplas, como as desenterias, as reações lepróticas intensas e subintrantes, os surtos erisipelatosos determinam uma média elevada na estatística da mortalidade do leprocômio.

Comunidade sem conforto, mal alimentada, portadora de doença crônica debilitante, sem medicação adequada e suficiente, teria forçosamente de apresentar as mais variadas associações mórbidas. A desesperança era quase geral, desde que, não criam em possíveis curas, sentiam que não mais seriam libertados do nosocômio. As enfermarias viviam superlotadas de prostrados, esperando apenas o alívio supremo para os seus sofrimentos.

Outro problema cruciante era a falta de água. A reserva líquida dos poços perfurados não era suficiente para as necessidades mínimas de higienização do leprosário.

Faltava tudo. Energia elétrica, água suficiente, remédios, alimentação... mas, o leprosário continuava a prestar benefícios.

A maioria dos internos vivia em enfermarias, privados de qualquer atividade, conseqüências das suas lesões: uns quase cegos, outros afônicos, outros com pronunciadas rinites impedindo-lhes a respiração e o restante com violentas crises reacionais próprias da moléstia quando em fase aguda ${ }^{25}$.

Os recursos para manutenção do leprosário eram, de modo geral, provenientes da caridade individual e coletiva. Algumas empresas e associações de trabalhadores contribuíam bem como

${ }^{24}$ PORTO, W. Revista Ceará Médico, 1953, p.44.

${ }^{25}$ PORTO, W. Revista Ceará Médico, 1953b, p.44. 
o estado, mas não havia uma regulamentação acerca dos direitos dos leprosos no que consistia à assistência pelos poderes constituídos. Nesse sentido, eram as doações que constituíam a principal fonte de renda na leprosaria cearense. Porém, os vários donativos que eram destinados aos leprosários, possuíam também uma relação com a religiosidade militante presente naquele universo temporal e espacial. Nos primeiros anos do leprosário, dois grupos filantrópicos o mantiveram: uma comissão de beneméritos cuja coordenação cabia ao Cel. Antônio Diogo, e outro grupo, coordenado pela Sra. Dagmar Gentil e outras insuspeitadas damas da sociedade local.

Talvez a compreensão desse universo religioso "militante" seja uma das chaves para o entendimento da ampla rede caritativa organizada para a construção e manutenção do leprosário da Canafístula (depois Antônio Diogo), mas não a principal. É importante frisar que, embora a lepra no Ceará tenha a sua história intimamente entrelaçada com as realizações e ações de caridade, não é possível descartar o lado racional, prático e profilático de tais medidas. Se no trato com o problema da lepra em Fortaleza, não tínhamos notícias de conflitos de ideias entre a religião e a medicina - pois não mais se creditava o acometimento da enfermidade aos pecados terrenos - para ambas, a lepra continuava terrível e carente de medidas drásticas em que a segregação e o afastamento dos sãos, eram as primeiras medidas lembradas.

Nos primeiros meses do ano de 1931, o Dr. Antônio Justa tentava sensibilizar a opinião pública acerca das condições físicas da instituição:

[...] a iluminação da leprosaria é feita pelo processo rotineiro, primitivo e inconveniente das lamparinas ou pequenos faróis de querosene. Da qualidade da luz e demais inconvenientes nem é preciso falar. Há, no entanto, o perigo de incêndio e a circunstância do preparo dos aparelhos de iluminação ser realizado pelos próprios lázaros, no interior das habitações. Todos sabem o quanto é precário o tacto e a sensibilidade dos leprosos e quanto deve ser perigoso terem eles que se locomover manuseando tais aparelhos de iluminação com combustíveis de fácil ignição ${ }^{26}$.

${ }^{26}$ JUSTA, A. Revista Ceará Médico, 1931, p. 38 
Nos seus artigos, o Dr. Antônio Justa pretendia atingir as autoridades competentes no sentido de ampliar as verbas para o melhoramento das condições de moradia dos leprosos que eram bastante precárias, pois a redução ou suspensão de pagamentos e subvenções federais, estaduais ou municipais era um fato bastante comum e corriqueiro. Assim, queixava-se o médico:

[...] em geral, as casas dos doentes estão com os telhados deteriorados e as portas e paredes desde 1928, não recebem pintura, nem caiação e os pisos de tijolos com largos interstícios, acumuladores de poeiras, muito melhorariam se fossem cimentados. Fica aqui nosso apelo a nunca desmentida generosidade e altruísmo dos cearenses ${ }^{27}$.

Apesar de todo o esforço para a segregação dos doentes cearenses na Canafístula, em nenhum momento há indícios de atos fisicamente violentos no processo de internação. A documentação consultada nos dá a perceber que no Ceará as internações davam-se através do convencimento pautado na pressão psicológica, exercida através dos jornais, dos médicos, dos vizinhos e mais tarde do rádio, cuja estratégia discursiva atingia diretamente ao doente e sua família ${ }^{28}$.

Advogamos que o combate e o trato com uma moléstia como a lepra vai ser muito importante na década de 1930 - principalmente durante o Estado Novo - para propiciar maior visibilidade ao governo federal. Embora não tenhamos conhecimento de uma abordagem acerca da lepra nos estudos que contemplam a Era Vargas, o investimento financeiro dedicado a essa enfermidade pelo Ministério da Educação e Saúde (MES) principalmente entre 1935 e 1945 foi muito alto. Se tomarmos somente a estrutura física das colônias (eram 32 em 1942), observase que foram empregadas grandes somas para construção, ampliação, reparos e manutenção dessas instituições. Essas gigantescas edificações por si mesmas representaram (no pós-1930 com mais propriedade) o símbolo visual da árdua batalha contra a terrível moléstia. Essas construções, por sua magnitude, não poderiam também ser vistas como mais uma estratégia de propaganda do Governo Federal? Não se tornaram os Leprosários, com suas estruturas físicas

\footnotetext{
27 JUSTA, A. Revista Ceará Médico, 1931b, p. 39.

${ }^{28}$ Tal impressão foi desfeita, quando uma pesquisa coordenada pelos Professores Gisafran Jucá e Zilda Lima, entre 2014 e 2016 , em que foram entrevistados cerca de vinte e cinco ex-pacientes do Leprosário Antônio Diogo (Canafístula), apontou situações de extremo constrangimento na condução compulsória de doentes ao leprosário.
} 
imensas mais um símbolo do qual o Estado Varguista apropriou-se para fins políticos? Embora não sejam estas questões fundamentais para o desenvolvimento deste trabalho, não há como negar que o Governo Federal, sob os auspícios de Getúlio Vargas, contribuiu como nenhum outro até então, para a ampliação do isolamento compulsório dos enfermos de lepra, como ficará muito visível na segunda parte deste ensaio.

\section{AS ACÕES SANITÁRIAS E A LEPRA NO ESPÍRITO SANTO}

A lepra, doença hoje denominada de hanseníase, certamente esteve presente no Espírito Santo, desde a chegada dos colonizadores. No entanto, só tivemos registro dessa doença no decorrer do século XIX. Encontramos a primeira alusão a doença na notícia trazida pelo Provedor da Saúde da Província do Espírito Santo, o médico Manoel Goulart de Souza, que, em 1881, dizia que a morfeia, um dos nomes pela qual a doença era conhecida, estava presente na província, mas destacava que esses casos não eram frequentes:

[...] nem essa enfermidade reina endemicamente em ponto algum da província; que os poucos casos se têm manifestado isoladamente; que sendo moléstia hereditária em duas ou três famílias, cedo ou tarde se tem declarado em seus membros; e, finalmente, que a circunstância de se terem manifestado aquelles casos em differentes pontos prova que a causa não depende da condição topográfica. ${ }^{29}$

Outra informação importante que nos permite afirmar quanto à presença da hanseníase no Espírito Santo são os dados apontados pela estatística de leprosos do Brasil realizada em 1877, quando se apurou um número de 1047 doentes no Brasil, sendo que o Espírito Santo aparece com um total de 28 casos, perfazendo $2,7 \%$ desses doentes, que estavam internados no Hospital dos Lázaros localizado no Rio de Janeiro.

Como a lepra não foi alvo de uma ação mais efetiva no combate à doença pelo Estado brasileiro, somente nos anos 20 do século XX é que voltamos a ter notícias sobre a lepra e os leprosos no Espírito Santo. Em 1921, o médico Belmiro Valverde, ao escrever um livro sobre

${ }^{29}$ Relatório de Marcelino de Assis Fontes, 1881, p. 351. 
essa doença, afirma que a doença estava no Espírito Santo dizendo, no entanto, que era rara. O fato é que até o advento do século XX, a lepra não recebeu por parte do Estado uma preocupação eficaz no controle e no cuidado com os leprosos. Estes eram verdadeiros párias, que antes de serem cuidados eram literalmente apartados da sociedade.

Embora nas primeiras décadas do século XX as autoridades médicas e governamentais passassem a se preocupar com a questão sanitária da população brasileira, a lepra continuou, no entanto, longe de ser a preocupação do movimento sanitário que se instalou nesse período.

Em 1927, o médico Pedro Fontes chegou ao Espírito Santo e assumiu a chefia do Serviço de Profilaxia da Lepra e Doenças Venéreas. Tão logo iniciou suas atividades, ele realizou um censo para verificar o número de leprosos existentes no Espírito Santo. Ainda em 1927 foi levantado um total de 22 casos, em 1931 esse número subiu para 370 casos notificados. Para conseguir realizar um diagnóstico dos casos de lepra, Pedro Fontes criou o Dispensário Central com laboratório de microscopia e sorologia, localizado em Vitória, Capital do Estado, em seguida foram criados outros laboratórios nas cidades de Alegre, Colatina, Mimoso, Muqui, Calçado e Afonso Cláudio. A ideia era mapear os casos existentes de lepra de norte a sul do Estado. Como os casos detectados eram muito elevados e não havia um hospital para abrigar esses doentes no Espírito Santo, Pedro Fontes começou a pleitear junto ao governo do Estado a criação de um leprosário, fato que vai se concretizar ainda na década de 1930.

Com Pedro Fontes as ações no combate à lepra começaram a se efetivar, mesmo que inicialmente essas ações fossem tímidas, o que pode ser explicado, como nos aponta $\mathrm{Cabral}^{30}$, em razão do Brasil viver nesse momento uma instabilidade política. Cada vez mais havia por parte do Estado uma preocupação em encontrar os doentes de lepra. Dessa forma, se estruturou um tripé cujo objetivo era interromper a transmissão da lepra. Esse tripé era constituído pelos leprosários, os dispensários e preventórios. Segundo Araújo, esse tripé configurava-se aparelhamento eficaz contra o combate à lepra:

Estes dispositivos foram considerados por Capanema como elementos de "ação especial" da administração pública, pois recairiam diretamente sobre pessoas determinadas, indivíduos doentes, suspeitos e contatos do enfermo. Entretanto, havia outra parte da administração relativa à "ação geral" que incidiria sobre a

${ }^{30}$ CABRAL, Dilma. Lepra, medicina e políticas de saúde no Brasil (1894-1934). Editora Fiocruz, Rio de Janeiro, 2013. 
população de forma abrangente através dos serviços de propaganda e educação sanitária ${ }^{31}$.

O levantamento do número de leprosos no Espírito Santo desde o final da década de 1920 estava sendo tocado pelo médico Pedro Fontes, enquanto não existia um hospital próprio para abrigar os enfermos pela lepra. Ele sugeriu que se criasse um local para onde iriam esses doentes, numa edificação construída na Ilha da Cal, ao mesmo tempo que acreditava que era preciso continuar com o levantamento do número de leprosos no Espírito Santo.

Percorrendo de Norte a Sul do Espírito Santo, Pedro Fontes apresentou um dado assustador quanto ao quantitativo dos doentes no estado. Para chegar a este dado, ele disse que andou por:

[...] todas as cidades, villas e logarejos do Estado. Onde quer que houvesse um caso suspeito, indicado pelo inquérito epidemiológico, por médicos ou mesmo por pessoas leigas idôneas, fosse fazenda, roça, em plena floresta, para lá se transportava esse digno auxiliar, a fim de examinar o caso $^{32}$.

Para corroborar a certeza que Pedro Fontes tinha que o número de leprosos existentes no Espírito Santo era muito maior do que se pensava inicialmente, ele afirma o seguinte:

\begin{abstract}
Quando assumi a direção deste Serviço [Profilaxia e combate à lepra] encontrei, realmente, fichados pelo extinto Serviço de profilaxia Rural- que aqui funcionava cerca de 5 anos e junto ao qual havia um serviço de Lepra e doenças Venéreasapenas 22 leprosos. No fim de algum tempo verifiquei que este número estava Aquém da realidade e resolvi fazer um inquérito. Percorri todo o Estado, entendendo-me pessoalmente com os médicos de diversas localidades e cheguei à conclusão de que havia no Estado do Espírito Santo, mais de 200 leprosos. ${ }^{33}$
\end{abstract}

\footnotetext{
${ }^{31}$ ARAÚJO, Tania Maria Araújo. Vivos no campo do esquecimento: lepra e isolamento compulsório no Espírito Santo: 1920-1962. Tese (Doutorado em História) - Programa de Pós-Graduação em História da Universidade Federal do Espírito Santo, Vitória/ES, 2020.

${ }^{32}$ FONTES, Apud SOUZA-ARAUJO, Heráclides César de. Contribuição á Epidemiologia e Prophylaxia da Leprano Norte do Brasil. Mem. Inst. Oswaldo Cruz, Rio de Janeiro, v. 27, n. 3, p. 165-337,set.1933.Disponível em:< http://www.scielo.br/scielo.php?script=sci_arttext\&pid=S007402761933000300001\&lng=en\&nrm=iso>. Acesso em: 21 de mar. De 2021. ${ }_{33}$ SOUZA-ARAUJO, Heráclides César de. A lepra no Espírito Santo e a sua prophylaxia: a "Colonia de Itanhenga" -Leprosario modelo. Mem. Inst. Oswaldo Cruz, Rio de Janeiro, v. 32, n. 4, p. 551-605, 1937. Disponível em:http://www.scielo.br/scielo.php?script=sci_arttext\&pid=S007402761937000400008\&lng=en\&nrm=iso. Acesso em: 22 de mar. de 2021.).
} 
Segundo Tania Maria de Araújo,

As vantagens do recenseamento, conforme tratadas por Pedro Fontes, podem ser vistas como um guia para a ação profilática no Espírito Santo, pois recolhia impressões e diretrizes úteis para a implantação da política isolacionista: mapeamento e identificação precisa dos doentes, dimensionamento dos serviços conforme os focos da doença e magnitude da endemia, sensibilização dos médicos para o diagnóstico e vigilância da lepra, reconhecimento da classe política sobre a necessidade de investimento, além da aproximação entre doente e profilaxia médica oficial. ${ }^{34}$

O isolamento emergencial dos leprosos na Ilha da Cal não seria suficiente para abrigar o total de 347 leprosos apontados pelo censo no ano de 1932. Dessa forma, Pedro Fontes resolveu buscar ajuda junto ao Interventor Federal que governava o Espírito Santo, João Punaro Bley na expectativa de construir um leprosário.

Ao assumir o Serviço de Profilaxia da Lepra, Pedro Fontes foi incessante na busca por identificar os doentes, organizando um serviço de profilaxia que irá se consolidar a partir dos anos 30. O médico acreditava que a lepra era um problema de calamidade e que era necessário encontrá-la onde estivesse, daí o lema “[...] A lepra é mais frequente do que parece, só não sendo encontrada quando não procurada $[\ldots]^{\prime 35}$.

Não se pode negar que a ação implementada por Pedro Fontes quando assumiu os serviços de profilaxia da lepra foi decisiva nas mudanças efetuadas na organização dos serviços de combate à doença. ${ }^{36} \mathrm{E}$ a partir do censo de Norte a Sul foi constatado que a incidência da doença se situava principalmente nas regiões interioranas. Assim, dos 719 leprosos encontrados no Espírito Santo em 1937, 441 concentravam-se nos seguintes municípios: Alegre (133), Colatina

\footnotetext{
${ }^{34}$ ARAÚJO, 2020, p. 180.

${ }^{35}$ FONTES, Apud SOUZA-ARAUJO, Heráclides César de. Contribuição á Epidemiologia e Prophylaxia da Leprano Norte do Brasil. Mem. Inst. Oswaldo Cruz, Rio de Janeiro , v. 27, n. 3, p. 165-337,set.1933.Disponível em: http://www.scielo.br/scielo.php?script=sci_arttext\&pid=S007402761933000300001\&lng=en\&nrm=iso. Acesso em: 23 de mar. de 2021 .

${ }^{36}$ FRANCO, Sebastião Pimentel; BARROS, Luiz Arthur Azevedo. A lepra no Espírito Santo: de fagueira ilusão à Colônia de Itanhenga Dimensões, Vitória, v. 34, p. 228-254, 2015. Disponível em <http://www.periodicos.ufes.br/dimensoes/article/view/11117/7764>. Acesso em: 23 de março de março de 2021.
} 
(83), Mimoso do Sul (77), Afonso Cláudio (59), Siqueira Campos (59) e Cachoeiro do Itapemirim (52).

Pedro Fontes tinha a certeza de que a construção do leprosário para isolamento compulsório dos doentes era uma necessidade. Em artigo publicado num jornal local teria dito:

\begin{abstract}
O leprosário é a arma mais eficiente de combate à lepra; sem ele não será possível organizar o serviço útil de prevenção contra o mal de Hansen. É a um tempo, benefício para o doente, que só no leprosário poderá receber tratamento regular e garantia para a população, preservada com a segregação dos leprosos, do seu contágio $^{37}$.
\end{abstract}

Como se pode observar, para Pedro Fontes era necessário isolamento da doença como forma de proteger os sãos. Para este médico, a preocupação principal não era o tratamento regular ao doente e sim a preocupação com o contágio da doença ${ }^{38}$. O isolamento compulsório dos indivíduos que apresentavam sintomas da lepra tornou-se uma realidade, embora existisse quem se posicionasse contrário a esta política. Porém, o modelo adotado no Espírito Santo foi mesmo de isolar os doentes, afastando-os do convívio de entes queridos ou mesmo vizinhos.

Em virtude do empenho e ações do médico Pedro Fontes, a construção do leprosário tornou-se uma realidade, seguindo o modelo Carville $^{39}$ assim como ocorria em outros espaços asilares. A obra do leprosário de Itanhenga no Espírito Santo foi iniciada em 1932 e em 1935 algumas edificações já estavam construídas, ocorrendo nessa época sua inauguração parcial. A

\footnotetext{
${ }^{37}$ SERVIÇO NACIONAL DE LEPRA. Relatório de suas atividades no ano de 1943. Apresentado pelo Dr. Ernani Agrícola. Pasta GCh 1935.09.02. Disponível em: < https://www.docvirt.com/docreader.net/arq.gc.h/10556>. Acesso em 20 de mar. 2021.

${ }^{38}$ FRANCO, Sebastião Pimentel; NOGUEIRA, André; MARLOW, Sérgio Luiz. A Colônia de Itanhenga (Espírito Santo): edificação e vida em (mais) um leprosário brasileiro. In: FRANCO, Sebastião Pimentel; NASCIMENTO, Dilene Raimundo do; SILVEIRA, Anny Jackeline Torres (Org.). Uma história brasileira das doenças. Belo Horizonte: Fino Traço, 2017. p. 295-323. v. 7.

${ }^{39}$ Segundo Lins $(2018$, p. 1) "Experiências diversas, no enfrentamento dos problemas de saúde pública e sociedade entre enfermos por lepra e os Hospitais de Lázaros, ocorreram ao longo de séculos. Em fins do século XIX, através da construção da Leprosário Nacional de Carville, na Louisiana (USA), se consolida uma solução arquitetônica que ficou conhecida como "Pavilhões Carville", utilizada como modelo adequado ao tratamento, passando a inspirar a concepção e construção de hospitais-colônias no Brasil. Os "Pavilhões Carville" (bungalow style dormitories) passaram a se configurar como denominação de tipologia arquitetônico-funcional de pavilhões isolados, setorizados por gênero, tamanhos, especificidades de tratamentos e unidades funcionais do conjunto hospitalar e de custódia, compondo "micro-cidades" projetadas com diversidade funcional de espaços de convivência e atividades. Essa tipologia guarda relação com soluções da cidade préindustrial empreendidas na City Garden, de Ebenezer Howard, na evolução aos falanstérios e familistérios do século XIX, praticados por urbanistas utopistas, tendo relação íntima com o interesse político de modernização das cidades”.
} 
inauguração completa só ocorreu em 1937, quando toda a edificação já estava concluída, tendo recebido uma lotação de 380 internos $^{40}$.

A escolha do local para edificação do leprosário não foi uma tarefa fácil. Várias áreas estavam sendo cogitadas para a sua edificação, tomando como referência que a área a ser escolhida deveria ter:

[...] ampla superfície plana que comportasse as instalações; abundância de água; proximidade com as rodovias que permitissem acesso mais ou menos facilitado para a Capital, sem contar naturalmente, com o requisito fundamental de isolamento do sítio em relação às áreas de maior povoamento nas regiões ${ }^{41}$

O custo total da obra de construção do leprosário contou com aporte financeiro da União e do governo estadual do Espírito Santo. A área total onde se instalou o complexo do leprosário era de 1.200 hectares, dividida em partes a saber: 665 hectares para a área da colônia, 200 hectares para o preventório que seria concluído em 1940 e 335 hectares para a colônia agrícola. Segundo Souza-Araújo o complexo do leprosário possuía 65 unidades, que era dividida em três zonas, a sadia, onde ficavam a casa do diretor e do administrador, a garagem, a casa do porteiro, a central telefônica e luz; a zona intermediária onde ficavam a casa das irmãs de caridade, um pavilhão de observação onde ficavam as pessoas suspeitas da doença, o parlatório, o laboratório, a farmácia, o almoxarifado, a cozinha e copa limpa; na zona doente ficavam o pavilhão de expurgo dos doentes, a escola, a prefeitura, o refeitório e copa dos doentes, a policlínica, a lavanderia, seis casas para funcionários doentes, três pavilhões para oficinas, banheiros coletivos para as oficinas, campo de futebol, manicômio-cadeia, 12 pavilhões, pavilhão de diversão, biblioteca, igreja, dois dormitórios para meninas, 20 casas para leprosos casados, necrotério e cemitério ${ }^{42}$.

\footnotetext{
${ }^{40}$ Convém destacar que desde 1935 o isolamento compulsório dos doentes de lepra já estava instituído de acordo com o que previa o Decreto n. 7.117 (CYPRESTE; VIEIRA, 2004).

${ }^{41}$ FRANCO, Sebastião Pimentel; NOGUEIRA, André; MARLOW, Sérgio Luiz. A Colônia de Itanhenga (Espírito Santo): edificação e vida em (mais) um leprosário brasileiro. In: FRANCO, Sebastião Pimentel; NASCIMENTO, Dilene Raimundo do; SILVEIRA, Anny Jackeline Torres (Org.). Uma história brasileira das doenças. Belo Horizonte: Fino Traço, 2017. p. 295-323. v. 7.

${ }^{4}$ SOUZA-ARAUJO, Heráclides César de. A lepra no Espirito Santo e a sua prophylaxia: a "Colonia de Itanhenga" - Leprosario modelo. Mem. Inst. Oswaldo Cruz, Rio de Janeiro, v. 32, n. 4, p. 551-605, $1937 . \quad$ Disponível em: 238 http://www.scielo.br/scielo.php?script=sci_arttext\&pid=S0074-02761937000400008\&lng=en\&nrm=iso. Acesso em: 5 nov. 2018.
} 
A União destinou para construção da colônia a quantia de 790:000\$, repassados entre 1933 e 1936, e com relação à participação financeira do governo estadual, estimou-se que teria contribuído “[...] mais ou menos com a mesma importância ${ }^{43}$ ”. Para que fosse recebido o:

[...] auxílio nas despesas da obra, Pedro Fontes foi atendido em pedido dirigido ao município de Vitória que arcou com a construção de um pavilhão Carville. Agradecido, o médico expressou sua satisfação em ofício publicado pelo Diário da Manhã onde também registra o apoio que recebera do Departamento Nacional do Café com doação de 3.000 sacas do produto, além do investimento do governo estadual na aquisição do terreno, instalações e fornecimento de água, luz e telefone (O LEPROSARIO ..., 1934). Da prefeitura de Vitória o auxílio foi de 25 contos e da venda das sacas de café apurou-se 240 contos $^{44}$.

A inauguração da Colônia de Itanhenga foi um grande acontecimento na capital do Espírito Santo, os jornais locais noticiavam a grande mobilização da sociedade local. No jornal Diário da Manhã, de 11 de abril de 1937, foi noticiado o "Programa das festas de Itanhenga", as indicações das autoridades presentes, entre elas o Ministro Capanema e do Interventor João Punaro Bley.

Sobre a instalação da colônia, extenso artigo informou sobre os 52 setores e serviços oferecidos no espaço, fazendo a descrição pormenorizada a respeito de cada um deles, de maneira que pessoas que não estiveram presentes aos festejos poderiam tomar conhecimento da dimensão da obra. Assim, o periódico conduz o leitor a uma "visita" pelo posto policial, residência de funcionários sãos, garagem, pavilhão administrativo, portaria, centro de luz e telefones, correio, pavilhão dos suspeitos, pavilhão de expurgo, escola, prefeitura, farmácia, laboratório, pavilhões para leprosos solteiros, residências para os doentes casados, dormitórios para meninos, refeitório, cozinha, lavanderia, pavilhões para leprosos inválidos, pavilhão para leprosos enfermos com outras doenças, pavilhão para leprosos tuberculosos, delegacia de polícia, manicômio, pavilhão de diversões, biblioteca, oficinas, pavilhão de clínica, campos de

${ }^{43}$ AGC/FGV CPDOC, GC h 1965.09.02, f. 151

${ }^{44}$ ARAÚJO, 2020, p 557. 
esporte, banheiros coletivos, casas para funcionários leprosos, igreja, cemitério, forno crematório, zona estabular, plantações frutíferas ${ }^{45}$.

A colônia de Itanhenga iniciou suas atividades com um total de 380 pessoas entre maio e outubro de 1937, conforme relato de Souza-Araujo ${ }^{46}$. Embora o censo promovido por Pedro Fontes apontasse número bem maior de doentes de lepra no Espírito Santo, a capacidade da Colônia naquele momento só permitia esse número de internos. Tanto assim, que o Interventor João Punaro Bley informava que a colônia seria ampliada graças a construção de 14 prédios para casados e um pavilhão especial para doenças intercorrentes. O que de fato aconteceu, tendo em vista que três anos após sua inauguração, a Colônia de Itanhenga já apresentava número maior de internos, totalizando 467 enfermos.

Segundo o relatório da Colônia de Itanhenga, diversos serviços eram oferecidos aos internos da Colônia que contava com dermatologistas, farmácia, laboratório e por enfermeiros, estes também doentes. O número de consultas médicas era elevado, assim como o atendimento dermatológico. Entretanto, o relatório do ano de 1946 aponta que muitos dos doentes acabavam não sendo assíduos ao tratamento, “[...] vamos empreender esforços para ver se conseguiremos que os doentes, alguns já desiludidos de tratamento, voltem a tratar-se" ${ }^{\$ 7}$. O negligenciamento do doente ao tratamento pode ser explicado em razão de que, para alguns destes, tais tratamentos não traziam benefícios, ao contrário, provocavam reações adversas o que por si só explicaria o desânimo dos doentes com os tratamentos disponíveis. Não podemos esquecer, como nos aponta Manini ${ }^{48}$, que as reações cutâneas em relação a alguns medicamentos provocavam sérias reações nos enfermos, como por exemplo a Chalmoogra, que causava grande desconforto aos doentes que, dessa forma, evitavam tomar essa medicação. Segundo Manini ${ }^{49}$, as principais reações seriam a aparição de sinais e sintomas de inflamações que resultavam em “[...] episódios agudos que ocorrem antes, durante e após o diagnóstico da doença e são provocados pela resposta imunológica do hospedeiro. As reações são responsáveis pelo aparecimento da maior parte das deformidades físicas". Tal situação pode ser explicada em

\footnotetext{
45 ARAÚJO, 2020.

${ }^{46}$ SOUZA-ARAUJO, Heráclides César de. A lepra no Espirito Santo e a sua prophylaxia: a "Colonia de Itanhenga" - Leprosario modelo. Mem. Inst. Oswaldo Cruz, Rio de Janeiro, v. 32, n. 4, p. 551-605, $1937 . \quad$ Disponível em:<238 http://www.scielo.br/scielo.php?script=sci_arttext\&pid=S0074-02761937000400008\&lng=en\&nrm=iso>. Acesso em: 5 nov. 2018.

${ }^{47}$ COLÔNIA DE ITANHENGA. Relatório, 1946. Cariacica, 1946

${ }^{48}$ MANINI, Marli Penteado. A evolução da terapêutica. In: MONTEIRO, Yara Nogueira (Org.). História da hanseníase no Brasil: silêncio e segregação. São Paulo: LEER/USP; Fundação Paulista Contra a Hanseníase; Intermeios, 2019. p. 49-58.

49 MANINI, 2019.
} 
razão de que, nesse momento inicial da Colônia, não existia ainda tratamento eficiente para a doença, o que certamente fazia com que muitos enfermos não apresentassem melhora após o início do tratamento. Alguns, inclusive, acabavam piorando muitas vezes em consequência das reações que a medicação oferecida causava ${ }^{50}$.

Além da não disponibilidade de medicamentos eficazes para a cura da doença, outros problemas eram vivenciados no leprosário de Itanhenga, tais como a falta de funcionários e eficiência do laboratório ${ }^{51}$. Esses não eram os únicos obstáculos para que os doentes fossem tratados, curados e disponíveis para receberem alta e voltarem às suas origens. Segundo o Serviço de lepra no Espírito Santo, nos anos de 1950, o estigma e o preconceito com os doentes de lepra impediam que doentes pudessem voltar ao convívio de suas vidas anteriores.

[...] Temos diversos doentes internados em condições de receberem alta hospitalar e transferência para tratamento em dispensário mas sempre surge um obstáculo a saída deles de leprosários: ora, si casados lá, não pode sair e deixar o outro cônjuge, ora é indivíduo já deshabituado ao trabalho e não se aguenta cá fora e o primordial fator é a repulsa da sociedade, invocando preconceitos lendários e milenários que já não devem existir mais hoje, a respeito da contagiosidade da lepra que os obriga a recolherem-se novamente ao leprosário, quando cá fóra, tentam sua reabilitação à vida de sociedade ${ }^{52}$.

Segundo Cunha, somente o uso das sulfonas possibilitou uma nova era no tratamento dos leprosos, sendo responsáveis [...] "por acabar com a contagiosidade do doente logo no início do tratamento, a sulfona revolucionou os quadros medicamentosos e impôs uma nova realidade para a profilaxia baseada no isolamento dos doentes entre os muros do leprosário; [...]"53. Interessante indagar que se a medicação a partir da sulfona redundaria numa melhora substancial do estado dos pacientes contaminados pela lepra, por que o número de altas não se

\footnotetext{
${ }^{50}$ A medicação disponível nos primeiros anos de existência da Colônia era injeções de chaulmoogras e Promin, uma droga do tipo sulfônico. Somente a partir de 1943 é que a Sulfona, medicação descoberta vai ser administrada aos enfermos. Nos anos 1940, outras medicações também eram administradas aos doentes como Diazone e Diaminoxil

${ }^{51}$ SERVIÇO DE LEPRA (Espírito Santo). Relatório Atividades, 1950. Vitória, 1950.

52 SERVIÇO DE LEPRA (Espírito Santo), 1950, p. 32.

${ }^{53}$ CUNHA, Vivian da Silva. O isolamento compulsório em questão: políticas de combate à lepra no Brasil (1920 - 1941). Dissertação (Mestrado em História das Ciências e da Saúde) - Fundação Oswaldo Cruz, Rio de Janeiro, 2005. Disponível em: <http://arca.icict.fiocruz.br/handle/icict/4004>. Acesso em: 20 mar. 2021. p. 113.
} 
concretizou? Segundo dados apontados por Mendonça [1959?] tal situação se daria por falta de assistência médica. Referindo-se ao número de altas, encontramos os seguintes resultados: de 1946-1949 teriam ocorrido 27 altas por ano, 10 doentes que haviam recebido alta teriam sido reinternados. Em verdade, outros fatores contribuíam para que esse número de altas não fosse elevado, sobretudo pelo fato de o doente não ter novamente espaço junto a familiares ou à comunidade onde antes estava inserido, tudo em razão do estigma que a doença carregava. Esses doentes não mais eram benvindos ao território onde anteriormente habitavam.

[...] Temos diversos doentes internados em condições de receberem alta hospitalar e transferência para tratamento em dispensário mas sempre surge um obstáculo a saída deles de leprosários: ora, si casados lá, não pode sair e deixar o outro cônjuge, ora é indivíduo já deshabituado ao trabalho e não se aguenta cá fora e o primordial fator é a repulsa da sociedade, invocando preconceitos lendários e milenários que já não devem existir mais hoje, a respeito da contagiosidade da lepra que os obriga a recolherem-se novamente ao leprosário, quando cá fóra, tentam sua reabilitação á vida de sociedade" ${ }^{54}$.

Embora o número de altas tenha sido pequeno, o uso de sulfonas será a responsável pelos resultados positivos no tratamento dos doentes, o que vai resultar num aumento do discurso em favor do fim do isolamento compulsório, que vai se concretizar a partir de maio de 1962, pelo decreto $\mathrm{n}^{\circ}$ 968. Segundo Maciel $^{55}$, a partir de então o tratamento dos doentes deveria ocorrer na assistência ambulatorial e na vigilância epidemiológica.

\section{CONCLUSÃO}

No apagar das luzes da década de 1920, a presença da lepra no Ceará era um fato incontestável. Do abandono total em que viviam os leprosos cearenses entregues à própria sorte,

\footnotetext{
${ }^{54}$ SERVIÇO DE LEPRA (Espírito Santo). Relatório Atividades, 1950. Vitória, 1950.

${ }^{55}$ MACIEL, Laurinda Rosa. "Em proveito dos sãos, perde o lázaro a liberdade": uma história das políticas públicas de combate à lepra no Brasil (1941-1962). 2007. Tese (Doutorado em História Social) - Universidade Federal Fluminense, Niterói, 2007. Disponível em: http://www.historia.uff.br/stricto/teses/Tese-2007_MACIEL_Laurinda_Rosa-S.pdf. Acesso em: 25 jan. 2021.
} 
passou-se à organização de ações filantrópicas cujo objetivo maior consistia no recolhimento dos enfermos das ruas e praças. Não pairam dúvidas que o Leprosário da Canafístula, depois Antônio Diogo, foi edificado visando o afastamento dos doentes das pessoas sãs. Porém, naquele momento, o isolamento compulsório era a única medida profilática aceitável em virtude do desconhecimento dos agentes etiológicos da doença e das suas formas de contágio bem como da pressão da imprensa e supostamente da sociedade. Nessa perspectiva, o Estado do Ceará tentou alinhar-se ao modelo e às práticas consideradas mais adequadas no trato com a enfermidade, sugeridas pelos grandes sanitaristas do país, pelo Regulamento de 1923 e pelos Congressos Internacionais

O Leprosário inaugurado em 1928, era uma instituição totalmente insalubre, e representou o papel de afastar os doentes dos sãos, porém, não foi suficiente para isolar todos os enfermos de lepra do estado, tanto que, em 1942, foi inaugurado outro leprosário, o Leprosário Antônio Justa, este sim, obedecendo rigorosamente todas as normas de funcionamento exigidas pelo Governo Federal. Fato que não significou o abandono do antigo leprosário pelas autoridades competentes.

Já no Espírito Santo, a colônia de Itanhenga foi recebida com grande entusiasmo pela sociedade capixaba, pois significou retirar de circulação pessoas contaminadas, corpos transmissores da terrível doença e, portanto, perigosos para a saúde pública. Assim, comemoraram-se a segregação e o banimento dos doentes do convívio social e familiar, sem perspectiva de retorno ao seu meio, mas em espaço inseguro do ponto de vista terapêutico. De certa maneira, uma reprise contemporânea dos funerais em vida.

Embora por lei estivesse definido o fim do isolamento compulsório, tanto no Ceará quanto no Espírito Santo, de fato, este tipo de internação persistiu, vigorando ainda nas décadas seguintes. Em verdade, o Decreto 968 não deu fim as internações compulsórias tanto assim que, em 1968, surge a Lei de $n^{\circ} 5.511$ de 15 de outubro que representaria “[...] o ato final para o isolamento dos doentes, pois revogou definitivamente a norma que o instituiu (lei $\mathrm{n}^{\circ} 610$, de 13 de janeiro de 1949) e a lei que regulamentava as altas dos doentes (lei $\mathrm{n}^{\circ} 1.045$, de 02 de janeiro de 1950)" ${ }^{\prime 56}$.

${ }^{56}$ LIMA, Zilda Maria Menezes Lima, JUCA, Gisafran Nazareno Mota. Memória Social da Hanseníase no Ceará. EDUECE, Fortaleza, 2016. P 209. 
Tanto o leprosário Antônio Diogo (ex-Canafístula), quanto o leprosário de Itanhenga, continuaram sua rotina recebendo internos mesmo após 1968. Os doentes de lepra, em razão do estigma em relação a sua enfermidade ou por verem nesses locais a possibilidade de tratamento garantido, continuaram buscando a instituição, talvez pensando na possibilidade de minorar seu sofrimento pela doença em si e, sobretudo, pelo estigma que a enfermidade causava.

\section{REFERÊNCIAS}

\section{Fontes}

BOLETIM COMEMORATIVO DAS BODAS DE PRATA DA COLÔNIA DA CANAFÍSTULA, Fortaleza, 1953.

COLÔNIA DE ITANHENGA. Relatório, 1946. Cariacica, 1946.

CONTINENTINO, Lincoln. Organização de Leprosários. Arquivos Capanema Rio de Janeiro, S.d.

Correio do Ceará, Fortaleza/CE, anos indicados.

Diário do Ceará, Fortaleza/CE, anos indicados.

Diário da Manhã, Vitória/ES, anos indicados ESPÍRITO SANTO. Relatório apresentado a Assembleia Legislativa da Província do Espírito Santo em sua sessão ordinária em 08 de março de 1881 pelo presidente Marcelino de Assis Tostes. Vitória: Tipografia da Victoria. 1881.

MENDONÇA, Moacyr Henriques de. Correspondência ao Diretor do Departamento Estadual de Saúde no ES. [1959?].

O Nordeste, Fortaleza/CE, anos indicados.

Revista Ceará Médico (Academia Cearense de Medicina). Fortaleza/CE, anos indicados.

Regimento do Departamento Nacional de Saúde - Profilaxia Especial da Lepra, Rio de Janeiro, 1923.

SERVIÇO DE LEPRA (Espírito Santo). Relatório Atividades, 1950. Vitória, 1950.

SOUZA-ARAUJO, Heráclides César de. Contribuição á Epidemiologia e Prophylaxia da Leprano Norte do Brasil. Mem. Inst. Oswaldo Cruz, Rio de Janeiro, v. 27, n. 3, p. 165-337, set.1933.

Disponível

em:

<http://www.scielo.br/scielo.php?script=sci_arttext\&pid=S007402761933000300001\&lng=en $\& n r m=i s o>$. Acesso em: 5 mar. 2021. 
SOUZA-ARAUJO, Heráclides César de. A lepra no Espírito Santo e a sua prophylaxia: a "Colonia de Itanhenga" -Leprosario modelo. Mem. Inst. Oswaldo Cruz, Rio de Janeiro, v. 32, n. $4, \quad$ p. 551-605, $1937 . \quad$ Disponível em: <http://www.scielo.br/scielo.php?script=sci_arttext\&pid=S007402761937000400008\&lng=en $\& n r m=i s o>$. Acesso em: 5 mar. De 2021

SERVIÇO NACIONAL DE LEPRA. Relatório de suas atividades no ano de 1943. Apresentado pelo Dr. Ernani Agrícola. Pasta GCh 1935.09.02. Disponível em: <https://www.docvirt.com/docreader.net/arq.gc.h/10556>. Acesso em 20 de mar. 2021.

\section{Obras Gerais}

ARAÙJO, Tania Maria de. Vivos no campo do esquecimento: lepra e isolamento compulsório no Espírito Santo (1937-1962). Tese (Doutorado em História) - Programa de Pós-Graduação em História da Universidade Federal do Espírito Santo. Vitória, 2020.

CABRAL, Dilma. Lepra, medicina e políticas de saúde no Brasil (1894-1934). Rio de Janeiro: Editoras Fiocruz, 2013.

CYPRESTE, Dora Martins; VIEIRA, Alda. Hospital Dr. Pedro Fontes, antiga Colônia de Itanhenga: hanseníase: do isolamento compulsório à ressocialização. Vitória: SECULT, 2014.

CUNHA, Vivian da Silva. O isolamento compulsório em questão: políticas de combate à lepra no Brasil (1920 - 1941). Dissertação (Mestrado em História das Ciências e da Saúde) Fundação Oswaldo Cruz, Rio de Janeiro, 2005.

FRANCO, Sebastião Pimentel; SILVA, Simone Santos de Almeida. Os depoimentos e o cotidiano da Colônia de Itanhenga no Espírito Santo: apontamentos iniciais. In: MAGALHÃES, Sonia Maria de; SILVA, Leicy Francisca da; MACIEL, Roseli Martins Tristão (Org.). História de doenças; percepções, conhecimentos e práticas. São Paulo: Alameda, 2017.

FRANCO, Sebastião Pimentel; BARROS, Luiz Arthur Azevedo. A lepra no Espírito Santo: de fagueira ilusão à Colônia de Itanhenga. Dimensões, Vitória, v. 34, p. 228-254, 2015. Disponível em: <http://www.periodicos.ufes.br/dimensoes/article/view/11117/7764>. Acesso em: 3 de mar. De 2021.

FRANCO, Sebastião Pimentel; NOGUEIRA, André; MARLOW, Sérgio Luiz. A Colônia de Itanhenga (Espírito Santo): edificação e vida em (mais) um leprosário brasileiro. In: FRANCO, Sebastião Pimentel; NASCIMENTO, Dilene Raimundo do; SILVEIRA, Anny Jackeline Torres (Org.). Uma história brasileira das doenças. Belo Horizonte: Fino Traço, 2017. p. 295-323. v. 7.

JUCÁ, Gisafran Nazareno Mota; LIMA, Zilda Maria Menezes. Uma História Social da Lepra no Ceará. Fortaleza, EDUECE, 2016.

LIMA, Nísia Trindade; HOCHMAN, Gilberto. Condenado pela raça, absolvido pela medicina: o Brasil descoberto pelo movimento sanitarista da Primeira República. In: MAIO, Marcos Chor, 
SANTOS, Ricardo Ventura (org.). Raça, ciência e sociedade. Rio de Janeiro: Fiocruz, Centro Cultural Banco do Brasil, 1996, p. 23-49.

LIMA, Zilda Maria Menezes. Uma enfermidade à flor da pele: a lepra em Fortaleza. Museu do Ceará/SECULT, Fortaleza, 2009.

LIMA, Zilda Maria Menezes. "O Grande Polvo de Mil Tentáculos”: a lepra em Fortaleza (1920-1942). Tese (Doutorado em História) - Programa de Pós-graduação em História da Universidade Federal do Rio de Janeiro. Rio de Janeiro, 2007.

LINS, André Bezerra. Dos pavilhões isolados "tipo Carville" de habitação coletiva em hospitais colônias no Brasil do século XIX, a racionalização projetual de "Micro cidades": revolução arquiteturial modernista de Luis Nunes no século XX. Disponível em https://www.researcgate.net/publication/337811059. Acesso em: 17 de mar. De 2021

MACIEL, Laurinda Rosa. “Em proveito dos sãos, perde o lázaro a liberdade”: uma história das políticas públicas de combate à lepra no Brasil (1941-1962). Tese (Doutorado em História Social) - Universidade Federal Fluminense, Niterói, 2007.

MAIO, Marcos Chor; SANTOS, Ricardo Ventura (Org.). Raça, ciência e sociedade, v. 1, Rio de Janeiro: Editora Fiocruz, 1996.

MANINI, Marli Penteado. A evolução terapêutica. In: MONTEIRO, Yara Nogueira (Org). História da hanseníase no Brasil: silêncio e segregação. São Paulo: Intermeios. 2019. 